eISSN 2582 - 0559

"An Official Journal of IDA - Madras Branch"(C2019.

Available online

\title{
TAKAYASU ARTERITIS - A CASE REPORT: WITH MAXILLOFACIAL SURGEON'S PERSPECTIVE AND BRIEF REVIEW OF LITERATURE
}

Dr. Ramesh Srinivasan V, Dr. Priyadharsana PS, Dr. Effie Edsor, Dr.Vigneswaran T, Dr.Gowri Shankar.P*. Department of Oral and Maxillofacial Surgery

*Department of Oral Pathology

RVS Dental College and Hospital, Coimbatore, Tamilnadu, India.

To access \& cite this article Website: jidam.idamadras.com

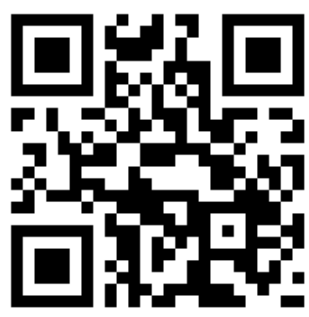

DOI:10.37841/jidam_2020_v7_i1_05

Address for correspondence:

Dr. Effie Edsor, MDS,

Assistant Professor, Department of Oral and Maxillofacial Surgery,

RVS Dental College and Hospital.

Coimbatore, Tamilnadu, India.

Email id: effieedsor@gmail.com

Received - 28.01.2020

Accepted - 27.02.2020

Published - 27.03.2020 that affects major vessels, mainly the aorta and its branches. The diseased condition leads to occlusion, stenosis, aneurysm or dilatations along the path of the affected artery. The etiology remains unknown. The disease has been reported worldwide, with an increased incidence in young Asian women. Like other medical condition, Takayasu arteritis patients will seek dental treatment. Hence the purpose of this article is to highlight the disease features and what a dentist should know or take precautions before treating them.

KEYWORDS: Takayasu Arteritis, Pulseless disease, Autoimmune. 


\section{INTRODUCTION}

Takayasu arteritis (TA) is also known as pulseless disease, aortoarteritis, aortic arch syndrome, idiopathic aortitis, occlusive thromboaortopathy, occlusive coagulant aortic syndrome, obstructive productive arteritis, reverse coarction or Martorell syndrome. ${ }^{1,2,5}$ TA is a chronic inflammatory arteritis affecting large vessels, predominantly the aorta and its main branches. The most affected branches are brachiocephalic, carotid, subclavian, vertebral, renal arteries, coronary and pulmonary arteries. ${ }^{3,4}$ Inflammatory disease leads to wall thickening, stenosis, fibrosis or thrombus formation. ${ }^{5}$

\section{HISTORY}

The disease is named after Mikito Takayasu, an Ophthalmologist, who reported ocular changes like aneurysms and arteriovenous anastomoses in patients with TA (1908). ${ }^{1,2}$ The disease is named after Takayasu who first reported a patient with TA, but there are other case reports of patients with TA in literature reported earlier. In 1830, Rokushu Yamamoto described a 45-year-old man with TA with features of persistent fever who later had no pulse in the right radial artery and weak pulse in the left radial artery. $^{2}$ In 1856, Savory presented a case report of TA in 22-year-old woman, with pulseless disease in both upper extremities and left neck. He later noticed on follow-up that the patient lost her vision. ${ }^{2}$ However, it was uncertain whether these cases truly suffered from TA.

Minoru Nakajima in 1921 compared his cases with previous reports and proposed that they should be considered as one disease. He characterized this disease by the following four criteria: (i) cases in young women affecting bilateral eyes; (ii) formation of arteriovenous anastomosis around the optic disc and microaneurysm in retinal vessels; (iii) decreased or loss of vision; and (iv) unpalpable radial artery. It was Minoru who termed it as 'Takayasu disease'. ${ }^{2}$ Later in 1948, neurosurgeons, Kentaro Shimizu and Keiji Sano from the University of Tokyo, called the disease as 'pulseless disease'.

The disease was entitled as 'occlusive coagulant aortic syndrome' by Maekawa and Kakei and 'obstructive productive arteritis' by Nasu. ${ }^{2}$ In 1965 , Riehl et al based on the pathological and immunological findings, concluded that TA is an autoimmune disease. ${ }^{2}$ American College of Rheumatology published a classification criteria for the disease in 1990 and described it as 'Takayasu arteritis'. Although both 'Takayasu arteritis' and 'Takayasu's arteritis' are used, in the Online Mendelian Inheritance in Man (OMIM) it is registered as 'Takayasu arteritis' and this term is more commonly used. ${ }^{2}$

\section{INCIDENCE}

Takayasu arteritis is a rare disease with worldwide distribution, being more common in Asian population. The incidence of TA was found to be approximately 1-2 per million population across the globe. ${ }^{6}$ Based on the recent epidemiologic study in Europe, the incidence of TA is more with an estimate varying from 0.4 to 1.5 cases per million population. The highest prevalence of TA is recorded in Japan (40 cases per million population) and the lowest in US (0.9 per million). ${ }^{6}$ The disease is more common in female with the female to male ratio of upto $8: 1 .^{2}$ The disease commonly presents in $2^{\text {nd }}$ or $3^{\text {rd }}$ decade of life but diagnosed in the later stage. ${ }^{5}$

\section{PATHOPHYSIOLOGY}

The predisposing and etiological factors of TA are still not clear. An autoimmune basis, influenced by genetic and environmental factors, is strongly suggested; the resulting inflammation is largely a cell-mediated immune response. An association between the extent of vascular involvement and the major genetic risk factor HLA-B*52 was found in Turkish TA patients, suggesting that genetic factors might influences the severity of the disease. ${ }^{8,9,10}$

\section{CLINICAL FEATURES}

Clinical manifestations of TA are nonspecific. The most common clinical features are decreased blood pressure (BP) and feeble pulse in the upper extremities, clammy skin and numbness in the fingers. ${ }^{11}$

The clinical course occurs in two stages; an early active inflammatory phase and late chronic phase. The duration of active phase lasts for weeks to months and may have a remitting and relapsing course. It is characterized by systemic symptoms like fever, malaise, night sweats, loss of appetite, headaches, dizziness, loss of weight, arthralgia, skin rashes etc. The former phase does not occur in all patients, but indigenous symptoms are often seen in children with TA. ${ }^{12}$

The chronic phase is due to arterial stenosis and/or occlusion and ischemia of organs. ${ }^{13}$ feeble pulses in $84-96 \%$, vascular bruits in $80-94 \%$, hypertension in $33-83 \%$, retinopathy upto $37 \%$, aortic regurgitation $20-24 \%$, congestive cardiac failure, seizures, postural dizziness, pulmonary artery involvement. ${ }^{5}$ Atypical presentation of homocystinuria in a TA has been recorded in $2013 .{ }^{14}$

\section{DIAGNOSIS}

Laboratory test for TA disease tends to be nonspecific. The erythrocyte sedimentation rate may be high, generally greater than $50 \mathrm{~mm} / \mathrm{h}$, in early disease but it is often paradoxically normal later. Leukocyte count may be normal or slightly elevated. A moderate, normochromic anaemia may be present in patients with advanced disease. Hypoalbuminemia with increased levels of $\mathrm{C}$ reactive protein, gamma globulin and fibrinogen are frequent findings. 15

The American Rheumatological Society 1990 considers three of the following six criteria necessary for a definite 
diagnosis of TA. ${ }^{16}$

1) Age of onset before 40 years

2) Claudication of extremities especially upper extremities

3) Decreased brachial artery pulse - unilaterally or bilaterally

4) $\mathrm{BP}$ difference $>10 \mathrm{~mm} \mathrm{Hg}$ in systolic blood pressure between both arms

5) On auscultation bruit over subclavian arteries or abdominal aorta

6) Arteriogram abnormality - narrowing or occlusion

ISHIKAWA'S CRITERIA FOR THE DIAGNOSIS OF TAKAYASU'S ARTERITIS ${ }^{17}$

Obligation criterion
Age $<40$ year (Symptoms of more than 1month
duration)
Two major criteria.
Stenosis or occlusion in the
1) Left mid subclavian artery
2) Right mid subclavian artery.
Nine minor criteria.
1) Raised ESR (persistent high ESR $>20 \mathrm{~mm} / \mathrm{h}$ )
2) Carotid artery tenderness (Unilateral or bilateral)
3) Persistent high blood pressure > 140/90mmHg
brachial or >160/90mmHg popliteal
4) Aortic regurgitation
5) Pulmonary artery lesion (Lobar or segmental arterial
6) Lesion in left mid common carotid artery
7) Distal brachiocephalic trunk lesion
8) Descending thoracic aorta lesion
9) Abdominal aorta lesion

In addition to obligatory criterion, the presence of major criteria or of one major and two or more minor criteria or of four minor criteria suggests high probability of the disease. ${ }^{17}$ Conventional radiographic angiography [digital subtraction angiography (DSA)] is the gold standard technique for diagnosis of TA. ${ }^{18}$ Recently non-invasive imaging methods including magnetic resonance angiography (MRA), colour doppler ultrasound (CDU), computerized tomography angiography (CTA), PET with 18F-fluorodeoxyglucose (18F-FDG) and 18F-FDG PET/CT have recently gained ground on DSA. ${ }^{19,20,21}$

\section{MANAGEMENT}

Corticosteroids and conventional immunosuppressive agents such as methotrexate (MTX), azathioprine (AZA), mycophenolic acid (MMF) and leflunomide (LEF) are the most commonly used agents for TA management. ${ }^{19}$ Biological drugs such as (TNF) tumour necrosing factor inhibitors, rituximab and tocilizumab are used in patients who are resistant to the above mentioned drugs. ${ }^{19}$

The frequency of ischaemic events in TA, may be decreased with the use of antiplatelet drugs. ${ }^{19}$ A retrospective study has concluded that antiplatelet therapy was associated with decreased frequency of ischaemic events in patients with TA. ${ }^{22,23}$

Surgical management involves balloon angioplasty or stent graft replacement. In long standing cases, surgical bypass of the affected segment is required. ${ }^{19}$ As a general rule, surgical intervention should be avoided during the active phase of the disease. ${ }^{19}$ Earlier diagnosis, better assessment of disease activity and clinical trials will improve the prognosis of TA.

\section{CASE REPORT}

A female patient aged 45 years reported to the outpatient ward with a chief complaint of shock like pain on left side of the face for past 8 years. Pain was of sudden onset, severe intensity with very short duration, radiating to the left shoulder. The pain aggravated in the morning and relieved in the noon. Patient was treated for trigeminal neuralgia for 4 years (gabapentin plus and zeptol)

Patient had the history of headache and before 4 years, she noticed numbness in both the upper limbs, percutaneous retrogasserian glycerol rhizotomy (PRGR) attempted but failed due to no cerebrospinal fluid (CSF) flow. She complained the history of weight loss of around $8 \mathrm{~kg}$ in past 5 years. With previous history and CT angiographic findings (Fig 1), patient was diagnosed as TA. Patient noticed watering of the left eye before 5 months and was advised steroid therapy. On intra-oral examination, patient had poor oral hygiene and grossly decayed 36. Left radial artery couldn't be palpated; the pulse and blood pressure were under normal limit. Since the patient was known case of TA, with physician consent, under antibiotic coverage, extraction of 36 was done due to poor prognosis. Patient reported for review with no fresh complaint, hence oral prophylaxis was done. The patient was advised to maintain oral hygiene and have a periodic dental visit. Since the patient was not on antiplatelet or on long term steroid, procedure was done only on antibiotic cover.

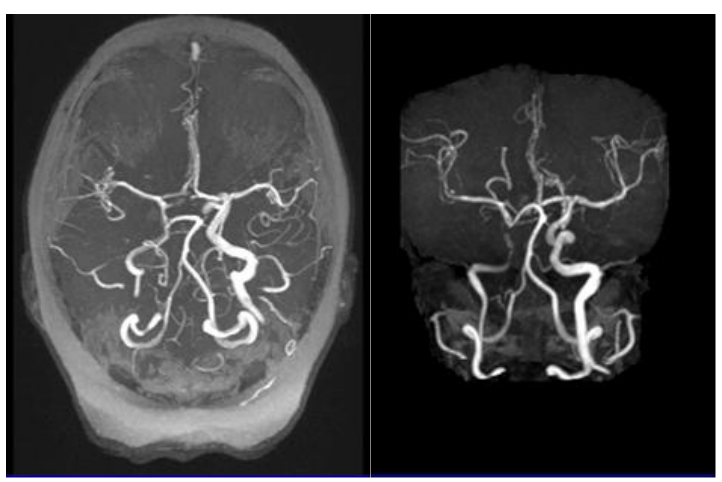

Fig 1: CT Angiogram of patient

MAXILLOFACIAL SURGEON'S PERSPECTIVE 
Adequate knowledge and proper diagnosis play a key role in the management of TA patients since it is a rare disease. Like other medical condition, early morning appointments to be made to avoid stress. During all dental procedures, patients head should be positioned in a relaxed way to avoid pressure or stress on the carotid sinus region which might lead to bradycardia. ${ }^{12}$ Gupta et al in his article has mentioned that dental surgical procedures preferably to be performed in the inactive phase (remission) of the disease. $^{12}$

Extraction or other surgical procedures should be carried out under antibiotic cover to prevent bacteremia and proliferation in the inflamed vessels. Most of TA patients are on high dose steroid therapy during the active phase. In such situation, the dosage of steroid must be doubled (rule of two) to prevent adrenal crisis.

The TA patients are prescribed antiplatelet therapy to prevent ischemic complications. Hence before surgical procedures cardiovascular monitoring should be done.

\section{CONCLUSION}

Maxillofacial and dental problems are inevitable in any patient. Detailed history, knowledge about the disease and management of medically compromised patient with extra precautions is mandatory to avoid complications.

\section{FINANCIAL SUPPORT AND SPONSORSHIP:}

Nil

\section{CONFLICTS OF INTEREST:}

There are no conflicts of interest.

\section{REFERENCES}

1. Duque C, Silva RC, Santos - Pinto L. Takayasu's arteritis: what should the dentist know? International journal of Pediatric dentistry. 2005 ;15:113-117.

2. Terao C and Dr. Mikito Takayasu. History of Takayasu arteritis. International journal of Rheumatic diseases. 2014; 17: 931-935.

3. Ishikawa K. Natural history and classification of occlusive thromboaortopathy (Takayasu's disease). Circulation. 1978;57(1):27-35.

4. Sharma BK, Sagar S, Singh AP, Suri S. Takayasu arteritis in India. Heart vessels suppl. 1992; 7:37-43.

5. Johnston SL,Lock RJ, Gompels MM. Takayasu arteritis: a review. J Clin Pathol. 2002; 55:481-486.
6. Onen F, Akkoc N. Epidemiology of Takayasu arteritis. La presse medicale. July-August 2017; 46(7-8): e197e203.

7. Marson A, Housley WJ, Hafler DA. Genetic basis of autoimmunity. The Journal of Clinical Investigation. June 2015;125(6): 2234-41.

8. Saruhan-Direskeneli G, Hughes T, Aksu K,Keser G, Coit P, Aydin S et al. Identification of multiple genetic susceptibility loci in Takayasu arteritis. Am J Hum Genet. 2013;93(2):298-30.

9. Sahin Z, Bicakcigil M, Aksu K, Kamali S, Akar S, Onen $\mathrm{F}$ et al. Takayasu's arteritis is associated with HLA-B*52, but not with HLA-B*51, in Turkey. Arthritis Res Ther 2012;14(1): R27.

10. Renauer P, Sawalha AH. The genetics of Takayasu arteritis. Presse Med. 2017, 46, e179-e187.

11. Mohan S, Lakshmi R. A case report on Takayasu's Arteritis. Int J Pharm Pharm Sci. 2017; 9(3): 296-297.

12. Sadurska E, Jawniak R, Majewski M, CzekajskaChehab E. Takayasu arteritis as a cause of arterial hypertension. Case report and literature review. Eur J Pediatr. 2012;171(5):863-869.

13. Khan MAM, Banoo H. A case report of Takayasu's arteritis. Medicine today. 2012; 24(02):79-81.

14. Manocha D, Kumar K, Anand R. Atypical presentation of a young female patient with Takayasu Arteritis: Case report and review of literature. Int $\mathbf{J}$ Clin Pediatr. 2013;2(1):34-36.

15. Manfrini O, Bugiardini R. Takayasu's arteritis: A case report and a brief review of the literature. Heart International 2006;2(1):66-71.

16. Arend WP, Michel BA, Bloch DA, Hunder GG, Calabrese LH, Edworthy SM et al. The American College of Rheumatology 1990 criteria for the classification of Takayasu arteritis.Arthritis Rheum. 1990 Aug;33(8):1129-34.

17. Ishikawa K. Diagnostic approach and proposed criteria for the clinical diagnosis of Takayasu's's arteriopathy. J Am Coll Cardiol 1988; 12:964-72.

18. Berlit P. Diagnosis and treatment of cerebral vasculitis. Ther Adv Neurol Disord. 2010;3(1):29-42.

19. Keser G, Direskeneli H, Aksu K. Management of Takayasu arteritis: a systematic review. Rheumatology 2014;53(5):793-801.

20. Gotway MB, Araoz PA, Macedo TA, Stanson AW, Higgins CB, Ring EJ. Imaging Findings in Takayasu's Arteritis. AJR;184, June 2005: 1945-50. 
21. Alibaz-Oner F, Aydin SZ, Direskeneli H. Recent advances in Takayasu's arteritis. European journal of Rheumatology. 2015; 1:24-30.

22. De Souza AWS, Machado NP, Pereira VM, Arraes AED, Reis Neto ET, Marizet HA al. Antiplatelet therapy for the prevention of arterial ischemic events in Takayasu arteritis. Circ J 2010; 74:1236-41.

23. Ueno M. Antiplatelet therapy in the treatment of Takayasu arteritis. Circ J 2010; 74:1079-80. 